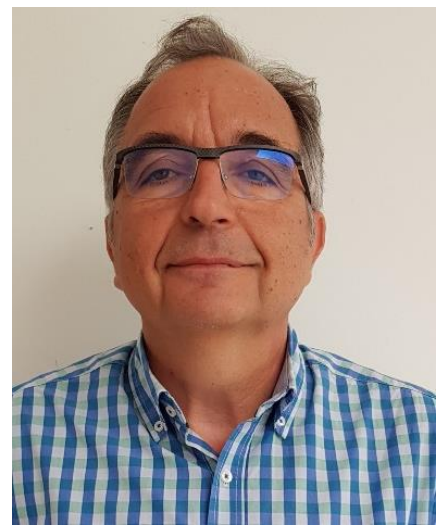

\title{
Sustainable Energy and Mobility as Drivers for the Economic Growth in the Mediterranean Islands
}

\author{
Professor Theocharis Tsoutsos \\ Director, Renewable and Sustainable Energy Lab \\ School of Environmental Engineering, Technical University of Crete \\ Polytechneioupolis, GR 73100 Chania \\ Email: theocharis.tsoutsos@enveng.tuc.gr
}

The "greening" of the inhabitant Mediterranean islands is crucial in order to build a sustainable future. Furthermore, the islands consist a major global tourism destination, so the potential minimization of their carbon footprint is essential for the success of the Paris Agreement.

The islands have the potential to be frontrunners in the clean energy transition by adopting new technologies, implementing and demonstrating innovative solutions, also for transport.

However, there is a number of challenges for their smooth operation and sustainability, such as:

- Energy safety, space use, road safety, air quality and noise pollution are some transport related issues that islands have to cope with.

- Islands are attractive as touristic destinations, feature a high pressure to their fantastic nature and sensitive ecosystems, which need special care and protection

- The seasonal fluctuation in their operation impacts on the design of their necessary infrastructure (ports, roads, energy supply systems)

- Although they should comply with the most recent national and international commitments, they are missing capacity, resources and social preparation for these changes.

Fostering a Mediterranean insular sustainable energy and mobility approach will also support the development of innovative, quality tourism products and services to make destinations even more attractive, as well as to address the mobility needs of citizens and visitors.

The above approach was discussed during the Public Hearing organized by the Network of the Insular Chambers of Commerce and Industry of the European Union (INSULEUR) and the Renewable and Sustainable Energy Systems Lab of the Technical University of Crete (ReSEL-TUC) on Friday $8^{\text {th }}$ of June 2018 at the premises of the European Economic and Social Committee (EESC), in Brussels. The event was organised in partnership with the EESC and was supported by the Conference of Peripheral Maritime Regions (CPMR) and the European Small Islands Federation (ESIN).

\section{About Professor Theocharis Tsoutsos}

Theocharis Tsoutsos is Professor, Head of Renewable and Sustainable Energy Lab (ReSEL) (2005- now), School of Environmental Engineering, Technical University of Crete; also the Director of Graduate Programme "Environmental Engineering" (2014-2018) and the Coordinator of the TUC-Energy Group (2013-2017) and the Head of Development Dept (Centre for Renewable Energy Sources \& Energy Saving - CRES (1992- 2005). He is a Member of Management Council (RMEI -réseau méditerranéen des ecoles d'ingénieurs et de management, 2018-now). He has coordinated 40+ projects on RES and energy efficiency; participated in 100+ totally.

Professor Tsoutsos is the author of $300+$ scientific publications in international journals, conference proceedings; He has 3,000+ citations h-factor:25 (Scopus); 29 (Google Scholar). He is also Editorial Board Member in the following peer-review international journals: Energies (2017-); AIMS Energy (2013-); Int. J. of Sust Built Environment (2015-now). He is a Project evaluator in European Research Council (ERC), REA (EC), ErasmusMundus (EC), GSRT (GR), State Scholarship Foundation (GR), Research Promotion Foundation (CY), Swiss National Science Foundation (SNSF); New Eurasia Foundation (RU); Netherlands Organization for Scientific Research (NL); Welsh Government (UK). 